\title{
Correspondence
}

\section{Chloramphenicol Misuse}

SIR,-As a clinical investigator in haematology, I was amazed and alarmed by an article entitled "Aberrant mRNA in Parkinsonism: Support for Hypothesis from Studies with Chloramphenicol" (Nature, 225, 962; 1970). My distress was caused by the simple fact that a dangerous drug (chloramphenicol) was used on human beings in large amounts, for a long time and for purely experimental reasons.

Chloramphenicol is an antibiotic which saves many lives threatened by certain rapidly proliferating bacterial invaders. It should never be used clinically unless there is danger to life and no other antibiotic will attack the specific bacterial cause of the infection. When clinically indicated, the usual daily dose is one-third of that reported in the article. In the treatment of bacterial infections, chloramphenicol is generally used for about a third of the time reported in this article. One course of treatment disqualifies the patient from a second course because the bone marrow appears to become sensitized for life and the patient may develop fatal aplastic anaemia. The course of treatment for Parkinsonism with chlor amphenicol is one that will most certainly maximize the probability of sensitizing the individuals to an antibiotic which might at some later date have been life-saving for the patient. The treatment given has a good probability of producing aplastic anaemia if used widely.

In the opinion of this haematologist, the experimental treatment described is to be condemned.

\section{Yours faithfully,}

\section{Eugene P. Cronkite}

Brookhaven National Laboratory, Associated Universitios, Inc., Upton, LINY 11973, USA.

ThIs letter has been shown to the authors of the article concerned, who reply as follows:

We are indebted to Dr Cronkite for providing us with the opportunity to bring up a number of points which, for reasons of space, were not adequately presented in our brief communication.

It has first to be re-emphasized that the use of chloramphenicol in Parkinsonian patients came as a natural consequence of a long experimental study which led to the hypothesis that a protein synthesis abnormality underlies the pathogenesis of Parkinson's disease. It was in the context of this hypothesis that CAP was chosen -among other metabolic inhibitors-mainly because of its known selective mechanism of action and of its comparatively minimal side-effects. Encouragement for its application was derived from a large-scale personal investigation which has revealed that despite the drug's wide use - and abuse-in this country only rare cases of haematotoxic reactions have been encountered and these were mild and readily reversible. Before deciding to conduct this clinical experiment which was crucial for our hypothesis, all the points raised by Dr Cronkite were considered and properly evaluated. All patients selected for this clinical experiment were free of allergic reaction, had never used CAP before and gave their consent for the treatment. Furthermore, all measures were taken, during the clinical trial, for early detection of toxic effects and eventual prompt discontinuation of treatment. Three out of the twenty-one initially included in the group developed slight gastrointestinal troubles and were excluded. In the final stage of treatment, three others developed a transient, slight hypochromia; in one of them this was associated with a drop in white cell count. The usual daily dose of CAP was $1.5 \mathrm{~g}$ and never exceeded $2 \mathrm{~g}$. This can hardly be called a high dose. The effective daily dose of CAP as reported in the literature ranges from 2 to $4 \mathrm{~g}$ (ref. 1 ).

But Dr Cronkite's main worry seems to lie in the eventual sensitization of our patients, so that they will be deprived of the benefit of a "life-saving" drug at a later date. Cases of sensitization are not reported in this country and this is also the case in other geographical regions $^{2}$. But even if regional factors are not considered, we would like to ask Dr Cronkite what likelihood there is of a given patient, in this small group of eighteen, to develop sensitization to CAP and to be invaded by bacterial agents which cannot be attacked by antibiotics other than CAP. Regardless of statistical probabilitiesand improbabilities-Dr Cronkite seems to be distressed by the fact that a drug has been used in patients for experimental reasons as if this were a novelty in medical sciences. Provided that a number of requirements are met not only by patients who, after all, may eventually benefit from a given drug, but also by healthy individuals, drugs-some of them with serious side-effects-have been and are currently being used for experimental reasons. CAP itself has been used extensively on healthy indivi. duals in amounts which could possibly cause great concern and not only to Dr Cronkite ${ }^{3,4}$. What, however, we consider would best relieve Dr Cronkite from his distress is the concluding phrase in our paper in which it is explicitly stated that "our emphasis on the beneficial effect of chloramphenicol on Parkinsonism is not meant to suggest a routine clinical use of the drug, but the results do indicate possible new approaches to the study of the pathogenesis and treatment of the disease". But even if it were intended for treatment, we would not expect Dr Cronkite to be selectively alarmed by the use of CAP as opposed to other antiparkinsonian drugs. We need not mention the too familiar example of L-DOPA, the administration of which in large amounts despite its reported high incidence of haemotoxic effects, has been fervently advocated by, among others, investigators in Brookhaven National Laboratories ${ }^{5}$.

It is on this similarity of action between the two drugs both on Parkinsonism and on blood that wo would welcome Dr Cronkite's comments and valuable opinion.

\section{Yours faithfully,}

C. N. Stefanis

Department of Neurology,

Athens National University,

Eginition Hospital,

74 Vasilissis Sophias Avenue, Athens, Greece.

1 Weinstein, L., The Pharracological Basis of Therapeutics (edit. by Goodman and Gilman), third ed., 1260

${ }^{2}$ Walter, A. M., and Heilmeyer, L., Antibiotica Fibel (second ed., Stuttgart, 1965).

${ }^{3}$ Saidi, P., Wallerstein, R. O., and Aggeler, P. M., J. Lab. Clin. Med., 57, 247 (196i)

4 Jiji, R. M., Gangarosa, E. J., and De Ta Macorra, F., Arch. Int. Med.,111, 70 (1963).

¿Cotzias, G., Papavassiliou, P. S., and Gallene, R., New Engl. J. Med.,280, $337(1969)$. 